\title{
CLINICAL AND HISTOPATHOLOGICAL CHARACTERIZATION OF LUPUS NEPHRITIS IN A TERTIARY HEALTH CENTRE, NORTH-EASTERN NIGERIA: REPORT OF FIVE CASES.
}

\author{
${ }^{1}$ Sulaiman MM, ${ }^{2}$ Zarami $\mathrm{AB},{ }^{3}$ Yerima A, ${ }^{1}$ Lawan $\mathrm{M},{ }^{2}$ Pindiga UH
}

${ }^{1}$ Renal Unit, Department of Medicine, College of Medical Sciences, University of Maiduguri

${ }^{2}$ Department of Histopathology, College of Medical Sciences, University of Maiduguri

${ }^{3}$ Rheumatology unit, Department of Medicine, University of Maiduguri Teaching Hospital

Correspondence and reprint request to: Dr Sulaiman Maina Mohammad, Department of Medicine, College of Medical Sciences, University of Maiduguri, PMB 1069, Maiduguri, Borno

State, Nigeria. Email: drsmmaina@unimaid.edu.ng_Phone: +234 8065980029

\begin{abstract}
Background: Lupus nephritis (LN) is an immune complex glomerulonephritis that complicates up to $40 \%$ of SLE patients. A kidney biopsy is required for diagnosis and staging of the disease. Case report: We report a cohort of five patients with LN from a tertiary health facility in northeastern Nigeria. The five patients were all women with age ranging from 26 to 55 years, and eGFR of between 6 to $154 \mathrm{ml} /$ minute. Four patients had normal kidney size and were biopsied whereas 1 patient had contracted kidney. Diffuse proliferative LN (Class IV) was seen in two patients while the other two patients had glomerular sclerosis (Class VI). Patients were given induction with methylprednisolone and mycophenolate mofetil (MMF). At one year follow up $2(40 \%)$ patients were in remission, $1(20 \%)$ was on maintenance hemodialysis and $2(40 \%)$ patients had died. Conclusion: Lupus nephritis is a common complication of SLE in northeastern Nigeria. Patients have features of advanced kidney disease at presentation.
\end{abstract}

Key words: Histopathologic features, Lupus nephritis, North-eastern Nigeria

\section{INTRODUCTION}

Lupus nephritis (LN) is an immune complex glomerulonephritis that develops as one of the severe organ manifestation of systemic lupus erythematosus (SLE) with ample morbidity and mortality. The pathogenesis is complex and involves immunological, environmental and genetic factors. ${ }^{1}$ SLE predominantly affects women of childbearing age, with a female to male ratio of $8: 1$ to $15: 1$; the incidence and prevalence of $\mathrm{LN}$ is, however, variable. ${ }^{2,3}$ The disease occurs in $40-75 \%$ of patients with SLE usually within five years of disease onset and can be an initial manifestation of SLE in most cases. ${ }^{2}$ SLE patients that are most likely

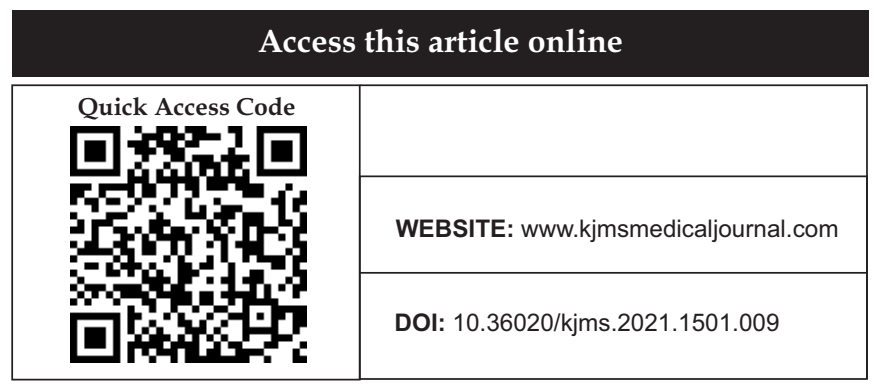

to develop LN are of younger age, males and black, Hispanic or of Asian ethnicity. Studies have shown that $60 \%$ of black SLE patients develop LN, with $25-50 \%$ having $\mathrm{LN}$ as an initial manifestation of SLE. ${ }^{4}$

The clinical presentation of LN is variable with most patients presenting with mild proteinuria and haematuria. Some patients will present with 'silent' LN (normal renal function and urinalysis), severe proteinuria (nephrotic syndrome), acute nephritic syndrome and/or acute kidney failure. Renal involvement in SLE is defined by persistent proteinuria (more than $0.5 \mathrm{~g}$ of protein per day, $3+$ on dipstick or a urinary protein to creatinine ratio or $24 \mathrm{~h}$ urinary protein excretion corresponding to 0.5 g daily) or the presence of cellular casts (either red blood cell, haemoglobin, granular, tubular or mixed) in urinary sediment.

Definitive diagnosis of $\mathrm{LN}$ is by kidney biopsy in which, LN is categorized into various histological 
patterns. The histological classification has evolved from the 1982 World Health Organization (WHO) classification to the 2003 International Society of Nephrology/Renal Pathology Society (ISN/RPS) classification class. ${ }^{7} 8$ Renal biopsy not only diagnoses LN, but also determines levels of activity, predicts prognosis and guides treatment protocols. ${ }^{9,10}$ All compartments of the kidney are affected in SLE-associated renal disease giving rise to a wide range of morphological changes which includes, mesangial or endocapillary proliferation, tubulointerstitial nephritis and thrombosis or necrotizing arteritis.

In a series of $79 \mathrm{LN}$ patients seen in Jordan, the commonest presentations were asymptomatic proteinuria and haematuria accounting for $59.5 \%$, followed by nephrotic syndrome $(22.8 \%)$ and nephritic syndrome $(17.7 \%) .{ }^{11}$ The most common histopathological types of LN were class IV (46.8\%), class V $(19.0 \%)$ and class III $(12.7 \%){ }^{2}$ Few cases of overlapping patterns have also been reported. ${ }^{9-11}$

Diagnosis of LN in developing countries is challenging due to delay in patients' presentation, lack of reliability of clinical features alone, difficulties performing biopsies, poor correlation between histopathologic and clinical features of the disease; and where biopsies are performed, there are difficulties in differentiating $\mathrm{LN}$ from overlapping conditions such as thrombotic microangiopathy, non-steroidal anti-inflammatory drugs (NSAIDs) interstitial nephritis, focal segmental glomerulosclerosis from other causes, and IgA nephropathy. ${ }^{12}$
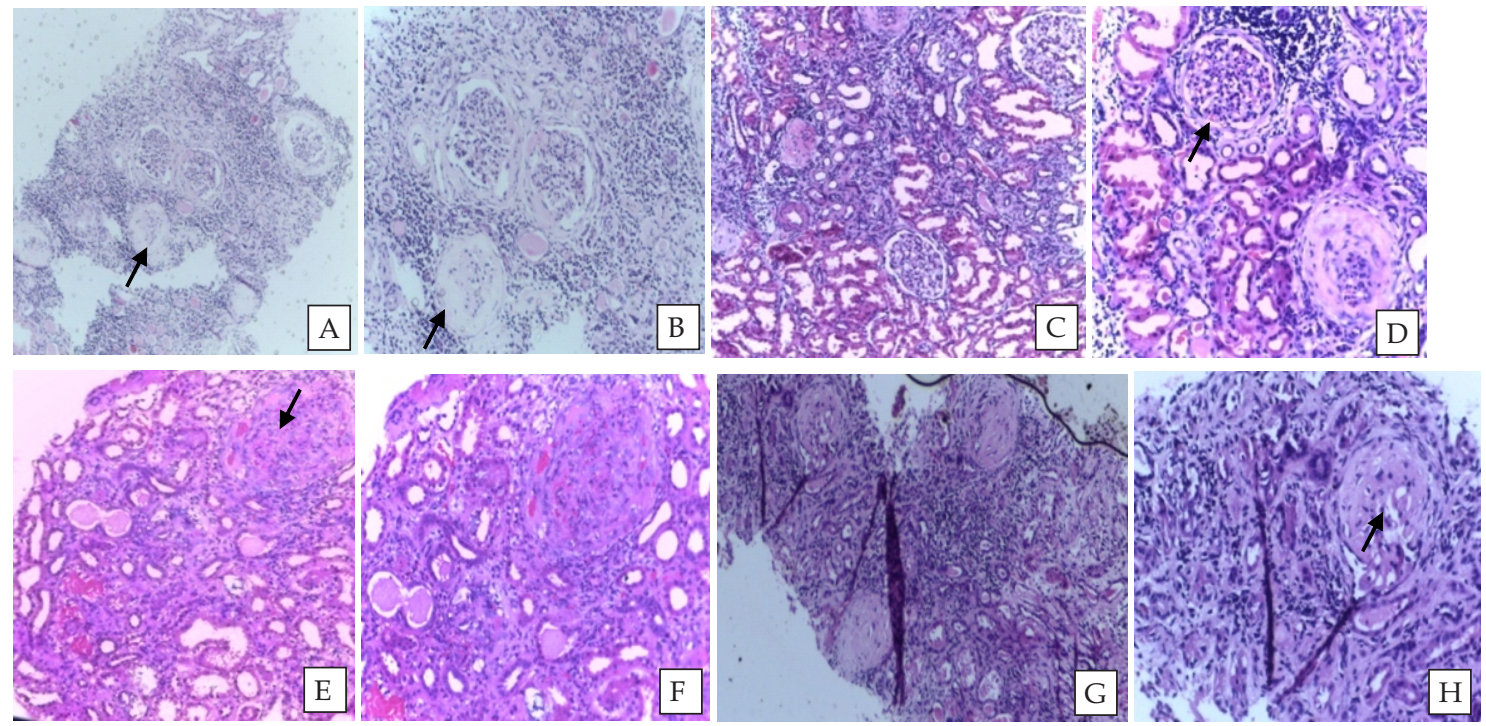

Figure 1: Photomicrographs of the four cases of LN; A, B and C, D show class IV LN with glomerulosclerosis (black arrows); E,F is class V LN and G,H shows class VI LN; H and E x100 and x200 each respectively. 
Table1: Clinical and laboratory characteristics of patients with Lupus nephritis

\begin{tabular}{|c|c|c|c|c|c|c|}
\hline \multirow[t]{2}{*}{ Characteristics } & \multicolumn{5}{|c|}{ Cases } & \multirow[t]{2}{*}{$\begin{array}{l}\text { Mean } \pm \text { SD/ } \\
\text { median (IQR) }\end{array}$} \\
\hline & 1 & 2 & 3 & 4 & 5 & \\
\hline Age (years) & 30 & 26 & 55 & 28 & 31 & $34 \pm 11.9$ \\
\hline Sex & $\mathrm{F}$ & $\mathrm{F}$ & $\mathrm{F}$ & $\mathrm{F}$ & $\mathrm{F}$ & \\
\hline $\begin{array}{l}\text { Duration of } \\
\text { symptoms (months) }\end{array}$ & 4 & 2 & 12 & 24 & 8 & $8.0(3-18)$ \\
\hline Clinical Diagnosis & CGN & NS & CGN & NS & CGN & \\
\hline Hypertension & Yes & No & Yes & Yes & Yes & \\
\hline PCV $(\%)$ & 24 & 31 & 34 & 26 & 33 & $29 \pm 4.3$ \\
\hline ESR (mm/Hour) & 43 & 127 & 55 & 84 & 39 & $55.0(41-105)$ \\
\hline ANA & Positive & Positive & Positive & Positive & Positi & \\
\hline Total Protein(g/dl) & 70 & 46 & 64 & 55 & 60 & $59 \pm 9.11$ \\
\hline Albumin (g/dl) & 12 & 14 & 21 & 18 & 26 & $18.2 \pm 5.6$ \\
\hline Creatinine $(\mu \mathrm{mol} / \mathrm{l})$ & 840 & 45 & 159 & 230 & 400 & $230.0(102-620)$ \\
\hline Urea(mmol/l) & 30 & 2.6 & 8.8 & 10.1 & 15.4 & $10.1(5.7-22.7)$ \\
\hline Proteinuria & $3+$ & $2+$ & $2+$ & $3+$ & $2+$ & \\
\hline Haematuria & $1+$ & $2+$ & $1+$ & $2+$ & $2+$ & \\
\hline eGFR & 6 & 154 & 36 & 28 & 14 & $28.0(10-95)$ \\
\hline ISN/RPS & IV & IV & $\mathrm{N} / \mathrm{A}$ & VI & VI & \\
\hline Kidney size (cm) & 11.9 & 10.4 & 8.8 & 10.5 & 9.7 & $10.2 \pm 1.1$ \\
\hline \multicolumn{7}{|l|}{ Right } \\
\hline Left & 11.8 & 9.7 & 8.2 & 10.4 & 10.0 & $10.0 \pm 1.3$ \\
\hline \multirow[t]{2}{*}{ Induction therapy } & $\mathrm{MP} / \mathrm{MMF}$ & $\mathrm{MP} / \mathrm{MMF}$ & $\mathrm{MP} / \mathrm{M}$ & $\mathrm{MP} / \mathrm{M}$ & \multirow{2}{*}{\multicolumn{2}{|c|}{$\mathrm{MP} / \mathrm{MMF}$}} \\
\hline & & & MF & MF & & \\
\hline \multirow{3}{*}{$\begin{array}{l}\text { Histopathologic } \\
\text { diagnosis }\end{array}$} & Diffuse & Diffuse & $\mathrm{N} / \mathrm{A}$ & Diffuse & \multirow{2}{*}{\multicolumn{2}{|c|}{$\begin{array}{l}\text { D iff u s e } \\
\text { sclerosis }\end{array}$}} \\
\hline & proliferative & proliferative & & sclerosis & & \\
\hline & $\mathrm{LN}$ & LN & & & & \\
\hline Outcome & Remission & Died & Died & $\begin{array}{l}\text { Partial } \\
\text { Remission }\end{array}$ & Dialys & \\
\hline
\end{tabular}

NB: TIN=Tubulointerstitial nephritis, ESRD=End stage renal disease, MPGN=Membranoproliferative glomerulonephritis, N/A= Not available.

Tables 2: Histopathological findings among patients with lupus nephritis

\begin{tabular}{llc}
\hline Type of lesion & $\begin{array}{l}\text { Number of patients } \\
(\mathbf{n}=\mathbf{4})\end{array}$ & Percentage (\%) \\
\hline No of glomeruli & 2 & 40 \\
\multicolumn{1}{c}{$<10$} & 2 & 40 \\
Glomerular sclerosis & 2 & 40 \\
MPGN & 2 & 40 \\
Tubular dilatation & 4 & 90 \\
Interstitial fibrosis & 3 & 60 \\
Interstitial inflammation & 3 & 60 \\
Vascular changes & 1 & 20 \\
\hline
\end{tabular}




\section{DISCUSSION}

This case series is the first reported biopsy confirmed LN in northeastern Nigeria and it showed that LN is common in our region. Our reported cases presented with advanced stages of kidney disease probably due to delayed diagnosis. This report highlights the need for an enhanced index of suspicion among health care providers as well as increased awareness of the inherent dangers of LN and SLE. Lupus nephritis can smoulder without symptoms in many SLE patients. ${ }^{16}$ Kidney biopsy is needed to provide accurate diagnosis and prognosis of kidney involvement in SLE patients. ${ }^{17}$ Lupus nephritis is the most feared complication of systemic lupus erythematosus. The contribution of SLE to the burden of end-stage renal disease in Nigeria is becoming more apparent. However, challenges remain due to the non-availability of diagnostic tests in many centres and the long turnaround time for the results of diagnostic investigations to become available. Patients are often diagnosed late because they usually spend time seeking care from traditional healers. This has resulted in a delay in the initiation of essential lifesaving disease-modifying treatment. Our patient cohort had a mean duration of symptoms of 8 months with a range between 2 to 24 months. This is similar to the study reported by Adelowo et $a l^{14}$ and Umezudike et $l^{15}$ in southern Nigeria.

Lupus nephritis predominantly affects women in their reproductive age with female: male ratio between 10-15:1. Males often lack typical features of SLE and coupled with lack of suspicion, many cases tend to be misdiagnosed. All our reported cases were females.

Our patients had a mean age of $30.0 \pm 11.9$ years similar to findings by Adelowo $e t a l^{15}$ whose patient cohort had a mean age of 30.4 years.

Nephrotic syndrome is a common clinical presentation of lupus nephritis especially among women of childbearing age. Other workers also reported that nephrotic syndrome is the commonest presentation of lupus nephritis. ${ }^{14-16}$ Our patients presented with a clinical diagnosis of CGN whereas $40 \%$ presented with features of nephritic syndrome. The majority of our patients have been diagnosed with hypertension. This is consistent with the histologic class they presented with at the time of diagnosis. Patients with class III, IV and VI usually have hypertension.
Diffuse proliferative lupus nephritis (RPS/ISN stage IV) is the commonest histologic abnormality seen from biopsy of LN patients and requires aggressive treatment with immunosuppressive drugs. Half of our patients had diffuse proliferative LN.

The management and prognosis of $\mathrm{LN}$ is determined by the underlying histopathologic stage and the extent of interstitial fibrosis. All our patients were treated with corticosteroids and MMF as induction therapy to avoid the side effects of cyclophosphamide therapy in childbearing young women. This contrast with the report by Ameh et $a l^{13}$ which showed that corticosteroid/cyclophosphamide combination was the most common drug combination used in lupus nephritis in Africa.

Two $(40 \%)$ of our patients died; one from complications of COVID-19 and the second from pulmonary embolism. The mortality rate in lupus nephritis was shown to range between $7.9-34.9 \%$ among African patients. ${ }^{19}$ Infections, cardiopulmonary involvement, and neurologic complications have been reported as the commonest causes of death in lupus patients. ${ }^{20}$

Our study is limited by the lack of immunofluorescence study of the biopsy specimen to define type and pattern of complement factor and antibody deposition in the kidneys. Assay of anti-double stranded DNA was not done due to its non-availability in our centre.

\section{CONCLUSION}

Lupus nephritis is a common complication of SLE among patients in northeastern Nigeria. We reported five patients with biopsy-confirmed lupus nephritis and their outcome will be improved with early diagnosis and prompt institution of immunosuppressive treatment.

\section{REFERENCES}

1. Lech $M$, Anders $H$. The pathogenesis of lupus nephritis. J Am Nephrol 2013; 24:13571366.

2. Schwartzman-Morris J, Putterman C. Gender differences in the pathogenesis and outcome of lupus and of lupus nephritis. Clin Dev Immunol 2012; 2021:604892. doi: 
10.1155/2012/604892.

3. Hanly JG, O'Keefe AG, Su L, Urowitz MB, Romero-Diaz J, Gordon $\mathrm{C}$ et al. The frequency and outcome of lupus nephritis: results from an international inception cohort study. Rheumatology 2016; $55: 252-262$.

d o i : 10.1093/rheumatology/kev311

4. Alarcon GS, Friedman AW, Straaton KV, Moulds JM, Lisse J, Bastian HM et al. Systemic lupus erythematosus in three ethnic groups: III. A comparison of characteristics early in the natural history of the LUMINA cohort. LUpus in MInority populations: NAture vs. nurture. Lupus 1999 ; $8: 197-209$. doi:10.1191/096120399678847704

5. Hochberg MC. Updating the American College of Rheumatology revised criteria for the classification of systemic lupus erythematosus. Arthritis Rheum 1997; 40(9):1725.

6. Petri M, Orbai AM, Alarcon GS, Gordon C, Merill JT, Fortin PR et al. Derivation and validation of the systemic lupus international collaborating clinics classification criteria for systemic lupus erythematosus. Arthritis Rheum. 2012; 64:2677-2686. doi:10.1002/art.34473

7. Churg J, Sobin LH: Renal Disease: Classification and Atlas of Glomerular Disease, Tokyo, Igaku-Shoin, 1982

8. Weening JJ, D'Agati VD, Schwartz MM, Seshan SS, Alpers CE, Appel GB, et al. The classification of glomerulonephritis in systemic lupus erythematosus revisited. JASN 2004; 15(2):241-250.

9. Almani S, Prokoper SD, Zhang J, Yu L, Avila-Casado C, Wither J, et al. Rethinking lupus nephritis classification on a molecular level. J Clin Med 2019; 8:1520.

10. Lager DJ. Classification of lupus nephritis: An update. Propath 2019; Available from; .

11. Farah RI, Dannoun E, Shahi NA, AIRyalat,
SA. Characteristic and histological types of lupus nephritis in a Jordanian tertiary medical centre. BioMed Res Int 2019; https://doi.org/10.1155/2019/7087461

12. Bihl GR, Petri M, Fine DM. Kidney biopsy in lupus nephritis: look before you leap. Nephrol Dial Transplant. 2006;21(7):1749-52.

13. Ameh OI, Kengne AP, Jayne D, Bello AK, Hodkinson B, Gcelu A, et al. Standard of treatment and outcomes of adults with lupus nephritis in Africa: a systematic review. Lupus. 2016; 25(11):1269-77.1.

14. Umeizudike TI, Awobusuyi JO, Amira CO, et al. Renal histology patterns in a prospective study of nephrology clinics in Lagos, Nigeria. Clin Nephrol. 2016; 86(13):119-22.

15. Adelowo OO, Umeizudike T, Olaosebikam $\mathrm{H}$, Awobusuyi JO. Nephritis as an initial diagnosis of lupus in Nigerian patients. A fr J Med Sci 2014; 43(2):99-105.

16. Gasporotto M, Gatto M, Binda V, Doria A, Moroni G. Lupus nephritis: clinical presentations and outcomes in the $21^{\text {st }}$ century. Rheumatology 2020; 59:v39-v51. doi: 10.1093/rheumatology/keaa381

17. Haladyj E, Cervera R. Do we still need renal biopsy in lupus nephritis? Rheumatologia 2016;54(2):61-66.

18. Komolafe OO. Rapidly progressive glomerulonephritis: A wild card manifestation of lupus nephritis. Saudi J Kid Dis Transpl 2018;29(2):443-451.

19. Yap DYH, Tang CSO, Ma MKM, Lam MF, Chan TM. Survival analysis and causes of mortality in patients with lupus nephritis. Nephrol Dial Transplant. 2012; 27(8):3248-54. doi:10.1093/ndt/gfs073.

20. Budhoo A, Mody GM, Dubula T, Patel N, Mody PG. Comparison of ethnicity, gender, age of onset and outcome in South Africans with systemic lupus erythematosus. Lupus. 2017 Apr;26(4):438-46.

Cite this article as: Sulaiman MM, Zarami AB, Yerima A, Lawan M, Pindiga UH. Clinical and histopathological characterization of lupus nephritis in a tertiary health centre, NorthEastern Nigeria: report of five cases. KJMS 2021; 15(1): 73 - 77. 